\title{
Evangélicos e a Nova Direita no Brasil: os Discursos Conservadores do "Neocalvinismo" e as Interlocuções com a Política
}

\author{
Gustavo de Alencar ${ }^{1}$
}

\section{Resumo}

A presença protestante em diversos setores da sociedade brasileira é bastante ampla e tem gerado muitos debates acadêmicos nos últimos anos. Para avançar na discussão envolvendo protestantismo e política, esse trabalho irá analisar um setor ainda pouco estudado do movimento evangélico: o neocalvinismo e suas conexões com a direita no Brasil. Com um perfil protestante tradicional, grupos neo-calvinistas, como Labri Brasil e a Igreja Esperança, através da figura dos seus líderes, tem se tornado importantes produtores de discursos e saberes, destinados a evangélicos, sobre temas como política, gênero, economia, ciência e cultura. Trata-se de grupos que possuem um perfil mais intelectualizado e que atraem parcelas da classe média evangélica que estão em busca de conteúdos mais especializados. Assim como ocorreu nos EUA, os conteúdos conservadores veiculados por tais grupos neocalvinistas reforçam o discurso e a agenda da direita conservadora. Mesmo sendo um grupo minoritário dentro do espectro evangélico, dada a importância dessa religião na configuração atual da sociedade, acredita-se que todo o esforço que vise aprofundar sua compreensão contribui para o debate científico.

Palavras-chave: Nova direita, Protestantismo, Neo-calvinismo, Direita cristã

\section{Evangelicals and the New Right in Brazil: The Conservative Speeches of "Neocalvinism" and its Entanglements with Politics}

Abstract

The Protestant presence in various sectors of Brazilian society is wide and has motivated many academic debates over the last years. To advance on the discussions regarding Protestantism and politics this work will focus its analysis on a sector of the evangelical movement very little studied so far: the neocalvinism and its conections to the right in Brazil. With a traditional protestant profile, neocalvinist groups such as Labri Brasil and the Esperança Church have become important producers of speech and knowledge targeting evangelicals about themes such as politics, gender, economy, science and culture. This groups possess a more intellectualized profile that attracts parts of the evangelical middle class that are seeking more specialized content. As well as it has happened in the USA, the conservative contents broadcasted by such neocalvinist groups strengthen the conservative right's speech and agenda. Even though they are a minor group within the evangelical specter, given

1 Programa de Pós-Graduação em Sociologia da Universidade Federal de Minas Gerais (UFMG) 
the importance of this religion in the social configuration nowadays, it is believed that every effort that thrives to deepen its comprehension contributes to the scientific debate.

Keywords: new right, protestantismo, neocalvinism, christian right

\section{Introdução}

$\mathrm{Na}$ atual conjuntura política do Brasil percebe-se o surgimento com mais intensidade de discursos conservadores associados àquilo que alguns analistas tem chamando de "nova direita" (CHALOUB \& PERLATTO, 2016; VELASCOS e CRUZ; KAYSEL; CODAS 2015) ${ }^{2}$. O crescimento da chamada nova direita não é exclusividade brasileira, já que é possível verificar em outras localidades na própria América Latina, na Europa e nos EUA uma expansão desse setor conservador da sociedade, que tem obtido sucesso em se articular cada vez mais. No caso do nosso país, só recentemente o fenômeno tem sido investigado. Luís Felipe Miguel (2016) ao discutir o avanço no debate público brasileiro de vozes abertamente conservadoras, afirma que seus discursos se baseiam em uma "conjugação heteróclita entre o 'libertarianismo', o fundamentalismo religioso e o antigo anticomunismo". Neste trabalho será discutida uma das facetas deste fundamentalismo religioso presente em um setor pouco estudado: o do protestantismo tradicional, histórico e intelectualizado que reproduz discursos que possuem profundas afinidades com as dos discursos reacionários que emergem na esfera pública do país.

Ao estudar de que maneira esses atores religiosos se articulam e buscam visibilidade dentro da sociedade, pode-se obter uma compreensão mais completa do campo evangélico, que é mais heterogêneo do que geralmente se assume, e da própria Nova Direita, que também apresenta diversidades internas. Escolhemos dois grupos situados na região metropolitana de Belo Horizonte como um caso empírico apropriado para se discutir e analisar o conteúdo do fundamentalismo religioso protestante: $\mathrm{O}$ L’abri Brasil e a Igreja Esperança. O primeiro é um grupo para-eclesiástico e o segundo uma igreja independente. Ambos são expoentes do protestantismo histórico e compartilham visões teológicas muito semelhantes. Embora minoritários, dentro do protestantismo brasileiro, entendemos que analisar setores ainda pouco estudados pela sociologia da religião irá contribuir com um aprofundamento das discussões a respeito das incursões dos evangélicos na arena pública brasileira. Por se tratar de um setor extremamente diverso, a forma de ativismo político dos evangélicos é composta de estratégias distintas e de repertórios simbólicos variados. Além disso, se o fundamentalismo religioso é uma das facetas que balizam as visões de mundo da guinada conservadora por qual passa a sociedade brasileira, entende-lo de forma mais profunda pode colaborar com um maior entendimento da conjuntura política pela qual passa o país.

\section{Em busca de uma caracterização da "Nova Direita"}

Os grupos conservadores e de direita são muito heterogêneos entre si e apresentam múltiplas facetas de forma que nem sempre é possível identificar de maneira clara características comuns que perpassam a multiplicidade de suas

2 O termo "nova direita" ainda não é um consenso entre os especialistas no assunto. Existem controvérsias a respeito dos fenômenos caracterizados como tais serem de fato "novos" ou se nada mais são do que um recrudescimento da mesma direita que sempre compôs o cenário político nacional. Entendemos que o adjetivo "nova" se justifica uma vez que os atores que hoje compõe o cenário da direita no Brasil parecem trazer novidades no que tange a conjugação do liberalismo econômico e conservadorismo nos valores, a forma de atuação nas redes sociais, a maneira através da qual grupos em torno dessas agendas são formados pela iniciativa civil e a forte centralidade dos temas culturais na retórica dos atores da nova direita. 
expressões. Além disso, o termo conservador e direita remetem necessariamente a um contexto relacional uma vez que essas identidades são construídas em oposição e relação a um conjunto de aportes ideológicos e valorativos considerados rivais. A direita alemã pode apresentar nuanças típicas do seu contexto e se diferencia da direita dos Estados Unidos e o conservadorismo que se apresenta hoje no Brasil, por conta de aspectos conjunturais próprios, pode ser diferente do conservadorismo que cresce na Hungria e Polônia. A orientação dada aos pesquisadores de tais fenômenos é não "essencializar" termos como conservador, fundamentalista, direita como se eles correspondessem a realidades estanques, absolutas e imutáveis (MEDVETZ e RUSSEL, 2011). Somente levando a sério o contexto relacional no qual surgem grupos de direita ou conservadores é que se poderá fazer uma análise adequada desses processos políticos e sociais. Com esta ressalva em mente, queremos destacar algumas características presente em grupos conservadores e de direita que compõe a esfera pública brasileira na medida em que seus valores mobilizados também estão presentes nos grupos protestantes que iremos analisar e descrever com mais detalhes à frente.

Os grupos de direita que emergem no cenário político brasileiro, assim como ocorre na Europa, estão reagindo a algo. No entanto, a forma como essa reação se configura em nosso país é bastante diferente daquela observada nos países que, a partir da segunda metade do século XX, consolidaram com sucesso um Estado de bem-estar social. Como dissemos acima, o recrudescimento da direita e do conservadorismo extrapola a conjuntura brasileira. No parlamento alemão, na Hungria, na Polônia e em outros países europeus é possível identificar a força que grupos conservadores possuem em se articular e obter representatividade no executivo e legislativo de seus respectivos países. Nesses contextos, a literatura especializada aponta para a existência de uma melancolia e desilusão nostálgica diante do cenário social e cultural da atualidade. A crise do Estado de Bem-Estar Social europeu fez com que saudosistas conservadores fortalecessem o sentimento de identidade nacional no entendimento de que foi o seu abandono que levou ao colapso da sociedade marcada hoje por taxa de desemprego elevada, crise econômica, aumento da criminalidade e a relativização de valores religiosos tradicionais. Só uma retomada do passado, a defesa de instituições tradicionais, e a exaltação do sentimento de grandiosidade nacional que se perdeu poderia fazer com que as "coisas voltassem ao normal" na percepção dos grupos conservadores e de direita europeus (MACHADO e MAIA, 2018).

O contexto brasileiro se configura de forma diferente uma vez que em decorrência da trajetória marcada por profunda desigualdades sociais, pobreza e limites na efetivação da cidadania, não existe um passado de desenvolvimento econômico e de bem-estar social claro a ser lembrado e rememorado. O passado colonial e escravocrata e sua força na estruturação da sociedade brasileira impede a lembrança de um momento de prosperidade vivenciado pelas classes trabalhadoras do país a não ser quando o fenômeno do lulismo entre os anos de 2003 e 2010 vigorou no país (SINGER, 2012). As classes médias, por sua vez, se articularam em torno de uma força conservadora que manifestou sua melancolia de maneira ramificada e multifacetada:

\footnotetext{
"Nesse contexto histórico, que dificilmente consegue sair do lugar de um devir de nação, é difícil pensar a melancolia ou a nostalgia como subjetividades que remetem a um passado nacional de abundância. Quem vestiu verde-amarelo nas manifestações a favor do impeachment de Dilma Rousseff não estava exaltando romanticamente um nacionalismo que se refere a um passado grandioso perdido, mas havia ali uma multiplicidade de perdas e frustrações. Se desesperança e a inconformidade pairam sobre o país, isso não ocorre de forma homogênea, mas se ramifica em distintas formas de vida e de viver a nação, fracionadas por classe, geração, estilo de vida e posição política”. (MACHADO e Maia, 2018, p. 28).
}

O conservadorismo brasileiro orienta sua 
reação à pluralidade de valores e emergência de novas configurações culturais em crescimento, principalmente no século XXI. Os estudos sobre o neoconservadorismo feitos por Habermas (2015) nos auxiliam a esmiuçar esse tipo de reação em mais detalhes. Ao analisar o discurso de lideranças neoconservadoras nos Estados Unidos e Alemanha que emergiram nas últimas décadas do século XX, Habermas afirma que sua retórica é marcada por uma relação dúbia diante da modernidade. $O$ que diferencia $o$ conservadorismo do neoconservadorismo é que este, ao contrário daquele, não rejeita todos os traços da modernidade, já que elogiam a industrialização, o desenvolvimento das relações de mercado e o crescimento capitalista. Os neoconservadores aceitam a "modernidade social", mas recusam a "modernidade cultural" em uma reconciliação seletiva com a modernidade (HABERMAS, 2015, p. 15-16). Desse modo, os intelectuais neoconservadores passam a ver as transformações culturais manifestas na mudança de valores e na maior autonomia individual como uma ameaça e um perigo para a ordem social:

"Para os neoconservadores, pois, moderna e desejável seria toda dinâmica social que nos conduz ao crescimento capitalista e ao progresso técnico e administrativo. Por outro lado, a continuidade mais plena dessas dinâmicas de progresso estaria ameaçada por perigos iminentes desencadeados pelas transformações aceleradas no campo da cultura. Desse modo, os diferentes representantes do neoconservadorismo atacariam a cultura profana moderna, seja denunciando seu caráter subversivo - 'ela contrasta com a disposição à produtividade e à obediência, da qual dependem funcionalmente uma economia eficiente e uma administração estatal racional' - sejam defendendo o esgotamento de seus potenciais criativos e a incapacidade de promover a integração social por si mesma”. (ibid, p. 17).

Esta reconciliação seletiva com a modernidade é uma marca dos grupos que nos servem de caso empírico, como será demonstrado posteriormente, e compõe um aspecto fundamental do ativismo conservador que emerge na esfera pública brasileira. Em seus diagnósticos a respeito da realidade, as mazelas sociais são percebidas como consequência de uma crise no campo da cultura que afeta a integração das pessoas na sociedade e as torna incapazes de se orientar num mundo em processo de intensas transformações. Neste tipo de visão neoconservadora, as instituições basilares da sociedade estariam ameaçadas e perdendo legitimidade diante da transformação cultural que exacerba o individualismo, a liberdade e a autonomia até últimas consequências. Sendo assim, o discurso da nova direita reflete a necessidade de delinear críticas ao pluralismo expresso pelas novas configurações familiares, pela transformação nos papeis de gênero, pela maior autonomia feminina, pela diversidade sexual e por outras manifestações da autonomia individual, entendendo que nelas estão a base da ruína social. As desilusões provocadas pelo sentimento de que o ordenamento social foi perdido são o principal motor da reação conservadora brasileira.

Atrelada ao neoconservadorismo, nos termos expostos acima, a reação conservadora da nova direita também se ancora na noção de pânicos morais. O conceito de pânico moral faz referência a "mecanismos de resistência e controle da transformação societária" (MISKOLCI, 2007, p. 103) diante de mudanças que são percebidas como repentinas e ameaçadoras para a ordem social. No caso de seu estudo, Miskolci analisa como o casamento gay e o avanço de pautas vinculadas a direitos LGBT promovem pânicos morais:

O casamento gay se tornou uma possibilidade que evoca temores com relação à sobrevivência da instituição em seu papel de mantenedor de toda uma ordem social, hierarquia entre os sexos, meio para a transmissão de propriedade e, principalmente, valores tradicionais. Assim, se a rejeição ao casamento gay reside neste pânico da mudança social, isto se dá porque nossa sociedade construiu historicamente a imagem de gays como uma ameaça ao status quo. (MISKOLCI, 2007, p. 
Diante do surgimento de novos movimentos sociais feministas, LGBT e identitários e da atuação crescente na esfera pública brasileira desses grupos nos anos 2000, viu-se emergir nos setores conservadores um pânico moral que entende as agendas promovidas por esses movimentos firam de morte a conformação social tradicional. A homossexualidade, em especial, é percebida por setores da nova direita como uma deturpação moral e uma ameaça à família. As relações entre pessoas do mesmo sexo como ilegítimas e imorais são estigmatizadas e os temores atualizados passam a se inserir em agendas políticas em torno das quais se alinham grupos conservadores. Como foi expresso por Luís Felipe Miguel, essa nova emergência do conservadorismo na sociedade brasileira tem como uma de suas bases o fundamentalismo religioso. Nossa tese é a de que o papel de grupos religiosos fundamentalistas reforça pânicos morais e atitudes neoconservadoras e servem de base intelectual e moral para discursos de setores da nova direita conservadora na sociedade brasileira atual.

\section{Evangélicos e sua inserção na sociedade} brasileira

A inserção dos evangélicos na sociedade e cultura brasileira tem sido um dos fenômenos mais estudados pela sociologia da religião no país, em uma tradição de pesquisa que busca perceber de que maneira as visões religiosas servem como mecanismo de mudança social (CAMARGO, 1973; FRESTON, 1993; MARIANO, 2011; SOUZA, 1969). A partir de uma herança weberiana, busca-se na religião um fator não de conservação do status quo e da coesão social, mas sua função na transformação de uma dada sociedade e na sua capacidade de moldar comportamentos e atitudes. A ênfase no movimento evangélico por parte dos estudiosos decorre da capacidade desta religião em articular visões de mundo que perpassam esferas não religiosas da vida social como política, economia, cultura, percepção dos papeis de gênero e sexualidade. $\mathrm{Na}$ perspectiva assumida neste trabalho, entendemos que o processo de secularização do mundo moderno não excluiu a religião da esfera pública nem sufocou sua capacidade de fornecer munição para a ação social em articulação com outros setores da sociedade (RANDOLPHO PAIVA, 2003). Sendo assim, cabe à sociologia da religião investigar as maneiras específicas por meio das quais se dá a presença pública das religiões nos mais variados contextos.

No caso específico dos evangélicos brasileiros é importante destacar que se trata de um grupo extremamente dinâmico em seu ativismo político e envolvimento com a sociedade (CUNHA, 2004; GIUMBELLI, 2008; MARIANO, 2016). Ao longo de sua inserção no Brasil sua maneira de se relacionar com a política e cultura se modificou bastante. Antonio Gouvêa Mendonça (1990 e 2004) demonstrou como as missões protestantes, principalmente vinda dos EUA, que chegaram no Brasil no século XIX, produziram uma religiosidade de tipo sectário que enfatizava a conversão de indivíduos para a nova fé. Em uma sociedade hegemonicamente católica, como era o Brasil da época, ser crente, evangélico e protestante era se opor aos traços culturais da sociedade que eram influenciados de forma profunda pelo catolicismo. Ronaldo Cavalcante (2010) utiliza a expressão "gueto" para caracterizar esse tipo de religião desenvolvida pelas missões estadunidense nas quais o cristão era incentivado a não ser envolver com o "mundo" por ser este ameaçador e marcado por aspectos pecaminosos contrários a vontade de Deus. Ser crente era sinônimo de não fumar, não beber, não participar de jogos de azar, não participar de festas e cerimônias religiosas, manter uma rigorosa disciplina moral. Basicamente os protestantes se excluíram da sociedade por entenderem que esta era marcada por valores opostos ao evangelho.

No campo da política, a tônica da falta de envolvimento evangélica era a ideia de que "crente não se envolve com política". A política era entendida como uma arena social marcada por jogos de interesses mundanos e pecaminosos 
que nada tinham a ver com a missão do crente e da igreja. Para estes a missão do evangélico era salvar almas, converter pessoas, entendendo por isso uma redefinição da identidade e do comportamento moral individual, se voltar para questões da vida após a morte e buscar a santidade. Desse modo, embora houvesse inserções de candidatos evangélicos na política antes da década de 1980, eles eram minoritários e não formaram alianças ou estruturam uma participação significativa e expressiva como se vê hoje na Bancada Evangélica.

Essa situação de timidez e reclusão social da parte dos evangélicos se alterou bastante nas últimas três décadas. Os evangélicos que no Censo do IBGE de 1980 compunham 6,6\% da população, passaram para $22,2 \%$, cerca de 42 milhões de pessoas, em 2010 (CAMURÇA in TEIXEIRA; MENEZES, 2013, p. 63). A expressão deste segmento religioso não se verifica apenas numericamente, já que desde 1980 a presença pública dos evangélicos tem aumentado a ponto de ser considerada uma das religiões mais dinâmicas do país. Emerson Giumbelli (2013) utiliza o conceito de "cultura pública" para designar o tipo de envolvimento que os evangélicos passaram a adotar diante da sociedade. Para Giumbelli, embora outras religiões como catolicismo e religiões de matriz africana possuam presença pública, são os evangélicos que agem de tal forma a atingir a sociedade "em muitas de suas diversas partes, através de ações que buscam tanto a ocupação de posições, quanto a proliferação de referências". (GIUMBELLI, 2013, p. 194). Os evangélicos passaram a participar ativamente de diversos setores da sociedade para ampliar sua influência. A discussão que se segue tem como objetivo demonstrar de que maneira dois grupos vinculados ao protestantismo histórico em seu ativismo político passaram a "proliferar referências" que impulsionam as agendas típicas da nova direita conservadora brasileira. Em textos, debates, seminários, palestras e vídeos a Igreja Esperança e o Labri Brasil difundem visões de mundo conservadoras que conformam práticas e a ação de setores conservadores na sociedade. Embora pouco expressivos numericamente, esses dois agentes religiosos são casos empíricos que permitem avaliar de que maneira se dá a conjugação de agendas e pautas conservadoras na sociedade com discursos religiosos de caráter fundamentalista. Abaixo descreveremos os grupos que serão analisados e os aportes teológicos específicos que os sustentam.

\section{O L’abri Brasil e A Igreja Esperança}

O L'abri ("o abrigo" em francês) é uma instituição religiosa fundada em 1955 na Suíça pelo teólogo estadunidense Francis Schaeffer e sua esposa Edith Schaeffer e tinha como um dos seus objetivos principais receber em casa pessoas com questionamentos existências e religiosos. Ao longo do ano, no Labri eram oferecidas aulas, estudos dirigidos, palestras sobre temas considerados relevantes para a sociedade contemporânea com o intuito de fornecer material intelectual e religioso para indivíduos, cristãos ou não, que buscavam respostas para dilemas de fé e pessoais. Parte significativa do público era de jovens, estudantes, músicos, artistas e outros teólogos. Os escritos e palestras de Schaeffer ganharam expressão de forma que o Labri passou a ser fundado em outros países como Austrália, Canada, Inglaterra, Holanda, Coréia, Estados Unidos, Brasil em casas (centros) com a proposta de acolher cristãos em seus desafios de fé e de oferecer um espaço para compartilhamento de experiência, desenvolvimento de práticas espirituais (leitura da bíblia, orações e meditações) e reflexão e estudo sobre temas diversos. Geralmente ao menos um casal de colaboradores do L'abri mora na casa onde funcionam as atividades, dentre as quais destaca-se retiros temáticos, ciclos de palestras, conferências, debates, rodas de leitura de textos teológicos, entre outros.

O Labri Brasil foi inaugurado em Belo Horizonte no ano de 2008 e desde 2017 se transferiu para a cidade de Lagoa Santa há 40 quilômetros da capital mineira. Em uma casa na qual mora a família do presidente e fundador do L'abri Brasil são recebidos jovens de todo o país em busca de instrumentação 
teológica e direcionamento espiritual. Entre suas principais atividades estão os termos de estudo ou "Nanotermos" que são períodos específicos ao longo do ano no qual o L'abri recebe pessoas para ficar na casa por períodos que variam de poucos dias a quatro semanas. Durante a estadia o estudante, com o auxílio de um tutor, define uma rotina de estudo, assiste palestras, participa das atividades domésticas - limpeza, cozinha, reforma da casa - e participa de atividades espirituais - cultos, orações, leitura da Bíblia - coletiva e individualmente. A proposta é que durante um período mais estendido no Labri o cristão seja munido de vasta instrumentação teológica acerca de assuntos variados e tenha um espaço para refletir sobre sua fé. $\mathrm{O}$ valor da estadia, que no ano de 2018 estava em R \$ 125,00 por dia, aponta para o fato de que geralmente quem frequenta a instituição são jovens de classe média e com alta escolaridade, profissionais liberais como médicos, advogados, engenheiros, psicólogos, etc.

Outra atividade oferecida pelo L’abri Brasil são os Retiros Temáticos que são realizados em finais de semanas ou em feriados prolongados como o que ocorre durante o carnaval. Sua função é discutir e oferecer palestras sobre temas considerados de relevância para a reflexão do cristão que está inserido na sociedade contemporânea. No ano de 2018 os retiros temáticos trabalharam assuntos como: "ideologia de gênero", esperança, problemas da alma, Deus e o Diabo nas redes sociais, As imagens de Jesus no Cinema e nas Artes, Esgotamento espiritual, entre outros. O valor do retiro varia de $\mathrm{R} \$ 320,00$ a $\mathrm{R} \$ 480,00$, o que faz com que o perfil de pessoas advindas da classe média prepondere também aqui.

Por fim, existe a Escola de Teologia do L'abri que oferece aulas nas noites de terça-feira e quarta-feira durante o primeiro semestre do ano. As turmas variam entre 30 a 40 estudantes e contam com professores colaboradores que se dividem para dar as aulas e abordar os temas do currículo. O investimento do curso é de dois mil reais e os estudantes além das aulas contam com uma tutoria de um dos obreiros do L’abri que estará disponível ao longo do período do curso para tirar dúvidas mais específicas, conversar de forma mais detida sobre dilemas de fé e receber uma orientação pastoral e espiritual. Existem também palestras abertas que ocorrem ao longo do ano que são frequentadas por ex-alunos da Escola de Teologia para atualizar suas reflexões teológicas.

O outro grupo que servirá de caso empírico para nossa análise é a Igreja Esperança, uma igreja independente que tem como pastor principal o presidente do Ĺabri Brasil. Outros de seus pastores também contribuem com o Labri em eventos e palestras promovidas ao longo do ano de forma que entendemos que em cultos, pregações e outras atividades, a referida igreja propaga visões teológicas e sobre a sociedade muito semelhantes àquelas expostas pelo L’abri. Fundada no ano de 2008, a igreja possui hoje cerca de 300 membros. É uma igreja protestante histórica que não está alinhada a nenhuma denominação específica, mas estáligada à tradição da Reforma Protestante e adota seus símbolos de fé $^{3}$. Seus membros são em grande parte jovens de classe média altamente escolarizados. Em seus cultos é muito comum verificar uma presença significativa de visitantes, que são pessoas que não querem sair da comunidade de fé da qual fazem parte, mas que procuram na Igreja Esperança um discurso teológico intelectualizado e mais bem fundamentado. É comum nas pregações que ocorrem na igreja ver os pastores fazerem referência a filósofos, teólogos, cientistas sociais, economistas e discutir temas como sexualidade, política e cultura em todas as atividades da igreja.

Nem o Labri Brasil nem a Igreja Esperança se constituem como fenômeno de massa capaz de articular uma quantidade de pessoas ao menos próxima a grupos pentecostais e lideranças

3 Os Símbolos de Fé são documentos, credos e confissões que definem a forma de pensar e viver a fé cristã. Trechos da Bíblia, documentos que decorreram dos primeiros concílios cristãos nos primeiros séculos desta religião e uma série de documentos redigidos no tempo da Reforma Protestante podem ser utilizados como Símbolos de fé. 
religiosas como Marcos Feliciano e Silas Malafaia. Ao longo desses dez anos de atuação na cidade de Belo Horizonte passaram cerca de 2 mil pessoas pelo L'abri em seus retiros espirituais e Escola de Teologia (com cerca de entre 30 a 40 estudantes em suas turmas anuais) e a Igreja Esperança também não chega à cifra de milhares de adeptos, como é comum nas igrejas de maior vitalidade do segmento evangélico brasileiro. Os líderes e pastores do L'abri Brasil e da Igreja Esperança tem sua influência mensurada muito mais naquilo que Habermas (2015) chama de "bolsa de valores intelectual". São grupos que dificilmente conseguirão eleger candidatos, ou mesmo conseguir levar um número significativo de evangélicos a votar em algum político específico, mas ao reunir intelectuais que discursam sobre temas de relevância social como política, cultura, ciência, gênero, educação, economia esses agentes religiosos fornecem bases mais sólidas nas quais outros líderes conservadores passam a se apoiar.

Os principais líderes das duas instituições participam de palestras em diversos estados e são convidados não só para eventos religiosos, mas também para palestras organizadas por coletivos cristãos em universidades. Em suas redes sociais, suas opiniões sobre política, economia, cultura e pautas sociais são vistas como guia para diversos cristãos, mesmo para aqueles que não estão filiados diretamente ao grupo. Magali do Nascimento Cunha (2018) tem chamado atenção para o ativismo evangélico realizado nas mídias sociais como sendo um dos principais elementos da participação desse setor religioso na esfera pública brasileira. O importante neste trabalho é ressaltar que, embora os discursos dos grupos que estamos estudando se vistam de uma roupagem muito diferente do evangelicalismo de massa com milhões de adeptos, por serem muito mais intelectualizados e rebuscados no que tange à mobilização de repertórios culturais, suas posições são bastante semelhantes quanto às posturas conservadoras e fundamentalistas a respeito de certas agendas sociais e culturais. Sabemos também dos limites desses grupos em influenciar de forma direta o ativismo político evangélico do país, mas menos do que mensurar articulações objetivas importa verificar a maneira que grupos, ainda que minoritários, se apropriam da religião para se posicionar publicamente sobre temas políticos, sociais e culturais.

\section{A teologia neo-calvinista}

As palestras, conferências, ciclos de debates, pregações, estudos dirigidos, termos de estudos oferecidos pelo L’abri Brasil e Igreja Esperança são balizados pela teologia neocalvinista. $O$ movimento que recebe o nome de neocalvinismo é uma matriz teológica que ganhou força na Holanda do século XIX e reverberou em muitos seminários teológicos dos Estados Unidos no século XX. Seu principal expoente foi Abraham Kuyper (1837-1920) que, além de teólogo, desempenhou funções públicas, inclusive, como primeiro-ministro da Holanda entre os anos de 1901 e 1905. Firmado na tradição reformada calvinista, Kuyper tinha como um dos seus objetivos renovar a vida social e religiosa da Holanda já que, em sua interpretação, existia uma crise na sociedade moderna que só poderia ser solucionada através da aplicação, na sociedade, de certos princípios religiosos.

$\mathrm{Na}$ visão de Kuyper o Modernismo, nome utilizado pelo autor para identificar um movimento histórico-cultural que supervalorizou a autonomia humana em detrimento de Deus, foi responsável por uma crise cultural e nos valores. Modernismo é entendido por Kuyper como um sistema de vida que abrange o pensamento e a experiência das pessoas e, por isso, só pode ser confrontado por outro sistema de vida igualmente abrangente. O sistema de vida que, por apresentar os princípios religiosos adequados, deveria ser utilizado para confrontar o Modernismo e todos os seus valores contrários aos preceitos de Deus, seria a vertente calvinista do Protestantismo que para o autor é a "única, decisiva, lícita e consistente defesa das nações protestantes contra o usurpador e esmagador Modernismo" (KUYPER,2003, p. 19-20). A proposta de Kuyper de atualizar a teologia calvinista para um novo contexto ficou conhecida como Neocalvinismo.

Na base da teologia neocalvinista está a ênfase 
em adaptar a religião às esferas não religiosas da vida. O Calvinismo é entendido como mais que uma religião, é "um sistema de vida abrangente" que transcende a esfera do sagrado. A própria separação entre duas esferas - sagrado e secular no Neocalvinismo é rejeitada em busca de uma fé mais integral. A integralidade da qual se fala aqui tem a ver com a aplicação de princípios da fé em todas as dimensões da vida. A frase de Kuyper, muito recorrente entre os autores neocalvinistas posteriores, expressa de forma clara a noção de que a religião abrange todos os setores da realidade: "Não há um só centímetro de todo o domínio de nossa existência sobre o qual Cristo, o qual é Soberano sobre tudo, não clame: é meu!" (ibid). A visão de política, o entendimento sobre o papel da educação, o conceito de família, a fé e a igreja, o lugar da ciência na sociedade, as relações econômicas, a presença da tecnologia na sociedade, a maneira de criar filhos, e todo o resto está diretamente ligado com a cosmovisão de cada um.

Para os neocalvinistas, o cristianismo produziu uma cosmovisão específica que colaborou com o desenvolvimento da sociedade. Ciência, formação de governos constitucionais, democracia, relações capitalistas, emancipação da arte como uma esfera distinta da religião institucional, indústria e agricultura, entre outras coisas, teriam sido impulsionadas e encorajadas pela cosmovisão calvinista. Nos dias de hoje, cabe aos cristãos inspirados pela cosmovisão calvinista promover novos desenvolvimentos capazes de impactar positivamente a sociedade. Existe, portanto, a cosmovisão cristã e cosmovisões que, por não serem cristãs, são idólatras. O ídolo é entendido como algo que substitui o papel e o lugar de Deus na vida das pessoas.

Francis Schaeffer, criador do Labri e um dos teólogos mais importantes para os líderes do L'abri Brasil e pastores da Igreja Esperança, é adepto da teologia neocalvinista e entende que uma cosmovisão cristã deve estar na base do engajamento do cristão na sociedade. Estudiosos já demonstraram que nos Estados Unidos as ideias de Francis Schaeffer cumpriram um papel fundamental no desenvolvimento da
Nova Direita Cristã. Manuel Castells afirma que Francis Schaeffer, através de sua vasta produção bibliográfica (que em parte está traduzida para o português), é um dos principais "mentores do fundamentalismo cristão contemporâneo" (CASTELLS, 1999, p. 37). O sociólogo David R. Swartz entende que Francis Schaeffer foi um "bastião do calvinismo ortodoxo" e teve um papel fundamental na formação da Christian Right nos EUA fornecendo um arcabouço teológico e racional para o engajamento cultural de diversos cristãos.

O movimento da direita cristã dos EUA nos anos 1970 e 1980 ganhou força através da aliança entre líderes religiosos e pastores com políticos ligados ao Partido Republicano (LIENESCH, 1982). Preocupados com a preservação de valores morais e religiosos em uma sociedade cada vez mais secular e plural, essas lideranças buscavam influenciar a sociedade civil através da conquista de espaços de representação local e nacional. Ao articular temas sensíveis de cunho moral e emocional, a direita cristã estadunidense passou a estar presente em conselhos comunitários, conselhos escolares e organizações partidárias. A organização Maioria Moral (Moral Majority) criada em 1979 pelo reverendo Jerry Falwell foi uma das iniciativas de maior sucesso em sua capacidade de mobilizar cristãos conservadores, influenciar políticas públicas e até exercer impacto nas eleições (BANWART, 2013). Embora não participasse diretamente de organizações como a Moral Majority, Francis Schaeffer - e sua teologia - serviu como guia intelectual para a fundamentação de muitos pregadores e políticos conservadores do período.

Uma das características presente na direita cristã estadunidense é o fato de seus adeptos estarem constantemente em busca de uma fonte de autoridade que possa servir de guia para seu envolvimento na sociedade (OWEN, Dennis; WALD, Kenneth; HILL, Samuel, 1991). Fontes de autoridade como versículos bíblicos, experiências religiosas confirmadas, opiniões de lideranças respeitadas é uma obsessão entre grupos religiosos fundamentalistas que acreditam que cada um de suas ações devem ser fundamentadas 
biblicamente. A fundamentação intelectual para a difusão dessa ideia na direita cristã estadunidense foi o próprio Francis Schaeffer:

"Esse evidente foco dos fundamentalistas na autoridade possui uma extensa fundamentação intelectual. Essa visão foi apresentada contemporaneamente de forma mais clara nos escritos de Francis Schaeffer, ele mesmo uma das autoridades citadas com mais frequência na literatura produzida pela imprensa evangélica. Ao defender o argumento fundamentalista de que a Bíblia é uma fonte de conhecimento factual, ou de “revelação proposicional' em termos teológicos, Francis Schaeffer desenvolve um argumento que oferece uma visão de mundo fundamentalista [...]”. (OWEN, Dennis; WALD, Kenneth; HILL, Samuel, 1991, p. 76)

A perspectiva de Francis Schaeffer é a de que sem um centro de autoridade promovido pelas leis de Deus e sem uma base cristã que fundamenta uma visão de mundo, não é possível diferenciar o certo do errado, o bom do mau. Não existiriam, na visão de mundo secular humanista, respostas para dilemas morais e por isso o mundo caminharia para um nível de incerteza e crise moral intensa. Na nova direita do Brasil argumentos muito semelhantes são encontrados, principalmente no que tange às questões de gênero e de sexualidade. $O$ conservadorismo que perpassa as opiniões e discursos da nova direita entendem, por exemplo, que a homossexualidade e as novas conformações dos papéis de gênero ameaçam a continuidade da instituição familiar. Em um entendimento bastante superficial, acredita-se que se houver flexibilização nas configurações familiares e alteração da moral sexual, não seria mais possível distinguir o que é certo e o que é errado e, consequentemente, estaríamos a um passo de aceitar práticas como a pedofilia. $\mathrm{O}$ argumento é que sem uma base sólida para definir os padrões de comportamento, os indivíduos ficam completamente perdidos nas questões morais, de forma que é imprescindível postular bases absolutas capazes de orientar a vida das pessoas. Para Francis Schaeffer e para os líderes dos grupos que estamos estudando, essa base é a Bíblia e a visão de mundo cristã.

O sociólogo Seth Dowland (2009) discute mais detidamente a utilização das agendas morais em torno dos valores da família pela direita cristã dos EUA e demonstra a centralidade do tema para a definição da identidade dos setores conservadores do país. A família é considerada uma instituição fundamental para o sucesso da América e se opor ao feminismo e às pautas LGBT é importante por serem iniciativas que ensinam, de acordo com a direita cristã, valores contrários à vontade de Deus e ao bom funcionamento da ordem social. Os movimentos sociais que visam a ampliação da autonomia e valorização da diversidade e pluralidade são entendidos como ataques à família, de maneira que esta instituição precisa ser defendida e preservada. Mais uma vez quem é o teólogo central no desenvolvimento desse raciocínio é o próprio Francis Schaeffer:

\footnotetext{
"Por volta do fim dos anos 1970, Schaeffer emergiu como o mais proeminente oponente evangélico do aborto, que ele retratou como a principal questão a demandar uma resposta Cristã. Em "Whatever Happend to the Human Race", que Schaeffer escreveu em colaboração com o futuro cirurgião geral C. Everett Koop, ele argumentou, 'De todos os assuntos relacionados à erosão da santidade da vida humana, o aborto é o ponto central'. Schaeffer argumentou que a permissão do aborto significou que a América havia abandonado o respeito à vida humana. O livro conectou o aborto a uma miríade de práticas desumanizadoras, incluindo a eutanásia, a tortura e o suicídio" (DOWLAND, 2009, p.612613)
}

Além de difundir ideais conservadores, o fundador do Labriteve um papelmuito importante ao insistir na necessidade de os evangélicos se engajarem ativamente nas questões políticas do país juntamente com os não evangélicos. A partir da noção de guerra cultural e "co-beligerância", Schaeffer sugeriu que era necessário desenvolver uma tática política que formasse e articulasse aliança entre todos aqueles que queriam lutar contra o aborto e contra a visões de mundo 
humanistas consideradas perigosas. Ao invés de um sectarismo baseado em critérios religiosos, grupos conservadores deveriam deixar suas divergências de lado para lutar com mais força a guerra cultural em curso no país. Desta forma, tanto nos EUA quanto no Brasil, a relevância do L’abri se dá menos em virtude do número dos seus adeptos e de sua capacidade de articular uma proporção significativa de evangélicos no país, e mais em sua capacidade de multiplicação de referências intelectuais e discursivas que servem de base para grupos que não necessariamente são evangélicos.

Da mesma forma que os discursos neocalvinistas difundidos por Francis Schaeffer foram centrais para a formação da direita estadunidense e grupos como a Maioria Moral, acreditamos que no caso brasileiro grupos como L'abri Brasil e Igreja Esperança tem cumprido uma função muito semelhante ao fornecer bases sólidas para visões de mundo conservadoras. Para a teologia neocalvinista é necessário que os cristãos percebam os conflitos existentes entre as cosmovisões cristã e não-cristã e se engajem na batalha cultural decorrente desta oposição. A batalha não se limita à pregação do evangelho com o objetivo de converter as almas das pessoas. O engajamento social e político dos cristãos deve almejar uma transformação dos princípios e valores que organizam a cultura, a sociedade e a política em suas mais amplas dimensões. Veremos de que maneira os discursos específicos do L'abri Brasil e da Igreja Esperança, bem como de suas lideranças, estão baseados em uma teologia, que conforme demonstramos, flerta com o fundamentalismo evangélico e difunde visões conservadoras sobre moral e costumes.

\section{Questões de gênero e sexualidade no discurso do L'abri Brasil e da Igreja Esperança}

Ao longo dos anos de 2015 e 2018 foram realizados trabalhos de campo no L’abri Brasil e Igreja Esperança. Pude participar de palestras oferecidas em ambos os grupos, conferências, retiros, pregações além de leitura de textos produzidos por seus líderes e veiculados em blogs e redes sociais. Foram realizadas algumas entrevistas e conversas informais com indivíduos vinculados às duas instituições religiosas com a finalidade de aprofundar na análise dos discursos e na reconstrução das bases que sustentam suas visões de mundo. Privilegiei palestras que tratassem do tema gênero e sexualidade por entender ser esta uma das pautas mais relevantes para o fundamentalismo religioso e um dos componentes centrais para a construção dos discursos da nova direita. Em torno da agenda da "defesa da família" ou dos "valores da família", grupos conservadores de diversas matizes formulam alianças para engajar na sociedade civil com a finalidade de promover políticas públicas baseadas em princípios morais, restringir a presença de novas configurações familiares e retomar padrões de controle da subjetividade (BIROLI, 2018).

Em três pregações realizadas na Igreja Esperança no ano de 2015 foi possível perceber a tentativa de fundamentar intelectual $e$ teologicamente posições conservadoras sobre sexualidade e gênero. Seus títulos são: "A mulher mais poderosa do mundo: o significado teológico da feminilidade", "O significado teológico da masculinidade" e "O que há de errado com a homossexualidade?”4. A primeira foi proferida no segundo domingo do mês de maio, data comemorativa do dia das mães, e se iniciou com uma passagem bíblica presente na Primeira Carta de Paulo a Timóteo capítulo 2 versículos 8-15 (1 Tm 2:8-15), que em suas palavras finais diz: "E Adão não foi iludido, mas a mulher, sendo enganada, caiu em transgressão. Todavia, será preservada através de sua missão de mãe, se ela permanecer em fé, e amor, e santificação, com

4 Todas as pregações estão disponíveis no youtube através dos seguintes links (acessados em 18/10/2017): https://www. youtube.com/watch?v=W3KmWx-laVk\&t=16s https://www.youtube.com/watch?v=_eZP5xkPgo4 https://www.youtube. com $/$ watch? $=$ rKClkIKWeKE\&t $=18 \mathrm{~s}$ 
bom senso" (grifo nosso). A partir da leitura do texto da Bíblia, o pastor titular da Igreja Esperança começou a articular seu argumento central de que a identidade feminina está e deve estar atrelada à maternidade. Movimentos feministas, nessa visão, contribuíram para a perda de identidade das mulheres na sociedade contemporânea, uma vez que em sua luta histórica contra o patriarcalismo a função de mãe foi deixada de lado e desprezada pela cultura, de forma que as mulheres estariam confusas a respeito de quem são. Essa crise identitária só pode ser solucionada com a observância da prescrição contida no texto e na aceitação pelas mulheres de seu papel, fundamentado na biologia e na teologia, de mãe. Rejeitar o propósito para o qual o corpo foi criado, como tem ocorrido em nossa cultura, seria um erro, um pecado, que precisa ser corrigido através do desenvolvimento de uma cosmovisão cristã que reconhece a função da "criação" de Deus. Com a finalidade de oferecer base intelectual para seu discurso, o pastor tenta atrelar a identidade feminina à maternidade, recorrendo a argumentos biológicos e científicos.

"Gênesis diz que o homem foi criado primeiro e depois a mulher. Então nós temos claramente aqui a liderança de oficio masculino que é um princípio bíblico. Você vai encontrar em Efésios, Colossenses, Coríntios e no Antigo Testamento. As mulheres não vão gostar disso, mas isso é um princípio bíblico [...] É um fato irritante, mas para alguém que, como eu, aceita a narrativa da ciência moderna, da evolução biológica, é um fato que está por toda a natureza”. (Caderno de Campo, dia 10 de Maio de 2015).

“E também olha para o seu corpo minha irmã. Por que que seu corpo é redondo? No bom sentido, claro, né... não me entenda mal [...]. Mas por que seu corpo é assim? Olhe para a forma do seu corpo. Por que você acha que você tem os quadris como você tem? Por que você acha que tem esses seios, os hormônios que você tem e por que você acha que tem esse aparelho reprodutor aí dentro? Porque isso é a sua finalidade do ponto de vista evolucionário e do ponto de vista biológico. Uma cultura que quer rejeitar isso está condenada. Condenada.
Definitivamente condenada. É claro que você pode ser muito mais do que uma fêmea. É claro que a mulher pode ser muito mais que uma fêmea. Fêmea existe de cachorro, de macaco, de gato. É claro que ser mulher é ser muito mais que uma fêmea. Mas ser mulher não é possível sem primeiro ser uma fêmea [...]. (ibid)

Ao longo da pregação é possível identificar a existência de uma distinção essencial e intrínseca entre homens e mulheres. A maternidade expressaria o destino biológico, social e teológico das mulheres cujo valor residiria no desempenho de seu papel como mães. Neste discurso, naturaliza-se convenções e posicionamentos simbólicos sobre o que é ser mulher e julga-se e condena-se aquelas mulheres que não querem ser mães ou optam por adiar a maternidade. Ao naturalizar e essencializar os papeis de gênero, a partir da mobilização de uma retórica com elementos científicos, o papel da mulher na sociedade e sua identidade é limitado à função de mãe. A ascensão do movimento feminista, a maior autonomia das mulheres e sua emancipação do papel materno são interpretados como uma confusão cultural que levou às mulheres a perda de sua identidade e apenas com um retorno à vontade de Deus e o desenvolvimento de uma postura humilde, como a de Maria, mãe de Jesus, que assumiu o papel de mãe obedientemente, as mulheres poderiam recuperar sua identidade e se encontrar no mundo.

No discurso acima, podemos identificar possíveis impactos a aspectos da cidadania feminina. Em uma sociedade na qual a responsabilização pelas tarefas domésticas não remuneradas e pelo cotidiano é desigual para homens e mulheres, "a fusão entre mulher e mãe continua sendo uma forma de controle e restrição da cidadania desse grupo que corresponde a mais da metade da população" (BIROLI ,2018, p. 112). A divisão sexual do trabalho doméstico libera os homens da função doméstica e atrela o cuidado dos filhos à responsabilidade primária das mulheres. Por mais que o pregador não assuma que a responsabilidade pelo cotidiano e pela criação dos filhos seja exclusividade das 
mulheres, ao associar sua identidade ao papel de mãe, um impacto político emerge afetando a inserção plena das mulheres no mercado de trabalho, que é uma condição essencial para a plena autonomia das mulheres no século XXI.

Na segunda pregação intitulada "o significado teológico da masculinidade" ${ }^{\text {, }}$, proferida apenas algumas semanas depois pelo mesmo pregador, é oferecida a complementação da posição a respeito dos papeis de gênero. Para o grupo, e isso é claramente identificado através desta pregação, gênero é um reflexo automático da biologia e dos ordenamentos de Deus identificados claramente na Bíblia. O título da pregação já indica a tônica do seu discurso: existe um significado teológico da masculinidade que se perdeu e que precisa ser resgatado. $\mathrm{Na}$ visão do pastor, existe um problema sério a partir do momento em que os cristãos não sabem mais quem são e não sabem mais "dizer para o mundo" ou explicar para a sociedade o significado de ser homem e de ser mulher. A perda de identidade se manifesta no fato de que o homem não sabe mais qual é o seu propósito e qual o significado da masculinidade. A recuperação da identidade e do significado da masculinidade se encontrariam no cristianismo:

\footnotetext{
“[...] para nós, não adianta você estudar biologia, psicologia, teoria queer, usar visões pósestruturalistas de gênero para você formar sua visão cristã sobre o que é ser masculino e sobre o que é ser feminino. Muito cristão quer dialogar com a cultura fazendo isso. Ele quer ser moderninho e quer adaptar essas categorias contemporâneas sem nunca submeter essas categorias a esse critério cristológico que é a pessoa de Jesus". (CARVALHO, 2015)
}

É necessário buscar na Bíblia, de acordo com essa visão, o significado do que é ser homem e mulher. O pastor leu trechos do livro de Gênesis para demonstrar que "Deus criou o homem à sua imagem e semelhança, macho e fêmea os criou" para dizer que masculinidade e a feminilidade expressam, os dois, a imagem de Deus. Vemos claramente aquela busca de autoridade presentena direita cristã estadunidense. Nesta interpretação fundamentalista, só é possível compreender de forma plena o que é ser humano e se situar e se posicionar no mundo em conexão com o que a Bíblia tem a dizer. Como decorrência desta visão, o cristão tem como obrigação se posicionar publicamente em defesa do casamento tal como definido por Deus:

\begin{abstract}
"Daí os irmãos podem ver a gravidade do desvio de parte da comunidade evangélica hoje que fica no deixa disso e não se compromete publicamente com o casamento cristão heterossexual. Não é apenas covardia moral, é uma ignorância teológica (ibid)

"Se você entende o que o casamento cristão significa não tem como você cometer uma barbaridade dessa que é ficar em silêncio diante do que o casamento está se tornando na cultura ocidental". (ibid)
\end{abstract}

A questão do casamento homossexual é melhor tratada pelo pastor na pregação proferida no dia 28 de junho de 2015 que tem como título "O que há de errado com a homossexualidade?". Enfatizamos o dia exato da pregação porque ela ocorreu apenas dois dias após a Suprema Corte dos EUA ter aprovado o casamento entre pessoas do mesmo sexo. O pregador inicia sua fala dizendo que evitou até o último momento possível esse tema, mas, em suas palavras, "o processo histórico me obrigou a tratar de certos assuntos" (Caderno de Campo, dia 28 de junto de $2015^{6}$ ). O assunto em questão é "o que há de errado, afinal de contas, com a homossexualidade? O que há de errado com isso?" (ibid). A resposta é que a homossexualidade é um pecado que tem como 
consequência a perda da identidade de homens e mulheres:

É um pecado junto com outros pecados. É um pecado. Não está em harmonia com o evangelho. Desafina com o evangelho. $\mathrm{O}$ homossexualismo não afina com o evangelho, não encaixa, não harmoniza [...]". (Caderno de Campo dia 28 de junho de 2015).

"Você que é homem não sabe mais porque você está aí. Você não sabe mais porque você tem esse negócio pendurado no meio das pernas. A mulher também não sabe também porque ela tá aí, ela não sabe porque ao invés de ter uma coisa pendurada nas pernas ela tem um buraco. Ela também não sabe. É muito básico, muito elementar: o homem não sabe porque ele tem essa conformação biológica e a mulher não sabe porque que tem essa. $E$ aí eles se confundem e começam a usar outros buracos e outras coisas e aí fica uma confusão danada. Então desculpa a franqueza irmãos, mas é isso que Paulo está falando". (Caderno de Campo, dia 28 de junho de 2015).

Rejeita-se como ilegítimas manifestações da diversidade sexual com base na utilização de passagens bíblicas que comprovariam a oposição de Deus a práticas homossexuais e de uma retórica supostamente científica que confere à biologia preponderância na configuração das identidades. A perspectiva da pregação é a de que existem formas corretas de se amar e de se relacionar em detrimento de outras que seriam desviantes e pecaminosas (BIROLI, 2018, p. 166). Nas palavras de Flávia Biroli, certos discursos conservadores afirmam "a superioridade de determinadas identidades ao mesmo tempo que se promove a desvalorização das vidas construídas como seu 'outro"' (ibid).

Além disso, a questão da homossexualidade extrapolaria a uma imoralidade pessoal e teria impactos para a construção da sociedade. Em uma retórica marcada pelo pânico moral, o pastor argumenta que por trás da legalização do casamento entre pessoas do mesmo sexo e das novas configurações familiares existe um projeto de civilização contrário aos preceitos de Deus. Esse projeto interviria na vida de cristãos desatentos que estão se perdendo diante dos desafios apresentados pela sociedade contemporânea:

"Isso se chama psicopolítica, uma intervenção política na sua vida e nos seus valores. E muito cristão acha que é moderninho e não sabe que tem um conjunto de ideólogos por trás do mercado e do Estado manipulando os sistemas de valores para produzir uma sociedade de bem-estar e de felicidade e você não passa de um Playmobil na mão desse pessoal. Se você acha que você é moderninho porque o Zuckeberg e você coloriu o seu perfil, meu irmão, você é um mané! Se você fez isso você é um grande mané. (ibid)

O argumento é o de que as políticas públicas de reconhecimento da pluralidade sexual, a maior presença do feminismo, a maior autonomia pessoal na direção da vida afetiva, a existência de múltiplas configurações familiares que são entendidas como avanços do ponto de vista da democracia e da cidadania, esconderiam uma ameaça séria à sociedade ocidental e à possibilidade de o cristianismo atuar de maneira pública na sociedade. Objetivos escusos e não revelados estariam sendo "empurrados" para a sociedade que está perdida em suas referências e bases de autoridade, e por isso aceita a flexibilização de seus valores. Como resultado dessa confusão e perda de identidade, as pautas de movimentos feministas e LGBT estariam avançando e destruindo os pilares civilizacionais representados por instituições como a família.

Em vários momentos, os líderes da Igreja Esperança e Labri afirmam que sua oposição às pautas LGBTs não são de ordem meramente moral e não se dá nos termos de enfrentamento de pecados individuais, mas se dão na dimensão de uma guerra cultural mais ampla. Existiria em curso um projeto civilizacional contrário à vontade de Deus em pleno desenvolvimento. $\mathrm{O}$ que estaria em jogo seriam cosmovisões de mundo, entendimentos ontológicos a respeito da realidade e definições sobre o significado e a identidade do ser humano. Acredita-se que 
com a difusão do movimento feminista e LGBT a própria existência do cristianismo como uma religião pública estaria ameaçada, uma vez que com o avanço das pautas progressistas não seria mais possível, na retórica de tais grupos, o exercício da liberdade do cristão em expor suas visões de mundo diante da sociedade. Em uma conferência ocorrida na Igreja Esperança em junho de 2018, um dos palestrantes e pastor principal da igreja afirmou:

“A questão homossexual não é só moral, existe um projeto de ser humano, um projeto de civilização e inclusive uma ameaça à democracia. O que está em jogo é a existência do cristianismo enquanto uma atividade pública. [...] O movimento LGBT é um movimento religioso que absolutiza a afetividade, não é um movimento de direitos de minorias". (Caderno de campo, dia 22 de junho de 2018).

Ao longo dos últimos dois anos, com a difusão mais clara de discursos conservadores na esfera pública brasileira, os líderes e pastores do L’abri Brasil e da Igreja Esperança começaram a se valer de termos de que não se valiam com tanta frequência, como "ideologia de gênero". No ano de 2017 e 2018 foram feitas palestras com essa expressão no título. Como aponta Maria das Dores Machado (2018), os discursos religiosos a respeito da ideologia de gênero servem de apoio para que sacerdotes, pastores e demais lideranças e ativistas cristãos sejam capazes de definir normas sociais e influenciar no desenvolvimento de políticas públicas. O gênero é visto pelo fundamentalismo religioso como de origem divina e biológica e qualquer tentativa de reconstrução e redefinição é entendida como uma ideologia que tem por objetivo destruir a família e os pilares da civilização ocidental. Além disso, a noção de que gênero é ideologia demonstra a percepção conservadora para a qual o conceito de gênero visa "esvaziar" o significado do que é ser homem ou mulher (BIROLI, 2018, p 169).

O tipo de discurso que surge em tais grupos expressa uma insatisfação moral perante transformações culturais, o desenvolvimento de uma visão maniqueísta de mundo, a idealização dos princípios econômicos liberais como a saída de boa parte dos problemas sociais e morais. É nesse sentido que entendemos que o Labri Brasil e a igreja Esperança possuem conexões com a Nova Direita. Não tanto por vínculos organizacionais oficiais ou repasse de verbas advindos de partidos conservadores, mas pela difusão de uma visão de mundo limitadora no que tange à diversidade sexual e de gênero, que vai contra progressos sociais claros nesta área. As visões de mundo expressas passam a moldar práticas, regular as formas como a sexualidade é experimentada e intervir nas configurações de gênero, valorizando de forma diferenciada os papeis sociais atribuídos a homens e mulheres. São restringidas novas configurações familiares reputadas ilegítimas e contrárias à vontade de Deus e seu plano para o desenvolvimento da sociedade.

\section{Conclusão}

Assim como os discursos neocalvinistas de Francis Schaeffer foram centrais para a formação da direita estadunidense, acreditamos que no caso brasileiro grupos como L'abri Brasil e Igreja Esperança, igualmente fundamentados no neocalvinismo de Schaeffer, tem se articulado nitidamente com a Nova Direita. Esperamos que o espaço para debater o fenômeno da Nova Direita e suas intersecções com a religião evangélica possa contribuir com a interpretação da atual conjuntura do país que aponta para uma participação cada vez maior dos evangélicos na sociedade, de forma que já não se pode fazer política sem se levar em conta o setor religioso que talvez seja responsável pela filiação de mais de um quarto da população do país.

A religião é uma importante instância valorativa capaz de moldar a ação dos indivíduos dando a eles ferramentas culturais de engajamento social e munição para agir em diversos contextos. Ao proporcionar subsídios intelectuais a um ativismo político religioso de cunho moral, os grupos protestantes estudados neste trabalho multiplicam as referências conservadoras da 
sociedade que passam a ser mobilizadas inclusive por não evangélicos. A face do fundamentalismo religioso presente na nova direita brasileira fornece de maneira especial conteúdo intelectual vinculado às pautas de "defesa da família" e dos "valores da família", que historicamente tem sido uma agenda capaz de mobilizar sentimentos morais e formar alianças na esfera pública entre setores conservadores distintos. Ao referendar visões sobre gênero e sexualidade a partir de conteúdo teológico e científico contribui-se para o desenvolvimento "da bolsa de valores" intelectual que fortalece posturas conservadoras a respeito da temática.

Acreditamos que os setores religiosos protestantes históricos no Brasil, que são minoritários, possuem uma importância muito grande em seu ativismo intelectual, que ainda não foi devidamente abordado. $O$ passo aqui dado pretende contribuir com as discussões do avanço dos discursos conservadores na esfera pública brasileira descortinando um de seus braços ainda pouco explorados. Há que se pensar, de que maneira existe tensões entre o tipo de intelectualismo dogmático apresentado por esses grupos e uma aparente onda antiintelectualismo de massa que parece ganhar força na esfera pública atual. Ao entender de forma mais profunda o entrelaçamento de visões de mundo religiosas com visões conservadoras da sociedade será possível compreender de maneira mais profunda os obstáculos que hoje se apresentam para a democracia do país, não só do ponto de vista institucional ou da perda da soberania nacional, mas do ponto de vista do desenvolvimento de agendas que se colocam contrárias à efetivação plena da cidadania e dos direitos individuais.

\section{Bibliografia}

BANWART, Doug. "Jerry Falwell, the rise of the Moral Majority, and the 1980 Election". Western Illinois Historical Review, vol. V, Spring, 2013. BIROLI, Flávia. Gênero e Desigualdade: limites da democracia no Brasil. São Paulo: Boitempo, 2018.

CARVALHO, Guilherme. Disponível em:https://www.youtube.com/watch?v=_ eZP5xkPgo4\&t=192s 2015. Acesso em 07/11/2017.

CASTELLS, Manuel. A era da informação: economia, sociedade e cultura, vol 2. O Poder da Identidade. São Paulo: Paz e Terra, 1999.

CHALOUB, Jorge Gomes de Souza; Perlatto, Fernando. "Intelectuais da Nova Direita no Brasil: ideias, retórica e prática política”. Insight Inteligência nº 72, jan-mar 2016.

DOWLAND, Seth. "Family Values' and the Formation of a Christian Right Agenda". Church History 78:3, September, 2009.

EDGELL, Penny. "A Cultural Sociology of Religion: New Directions". Annual Review of Sociology, 2012.

GIUMBELLI, Emerson. "A presença do religioso no espaço público: modalidades no Brasil". Religião e Sociedade, v.28, n.2, p.80-101, 2008.

"Cultura pública: evangélicos y su presencia en la sociedad brasileña". Sociedad y Religión, v.23, n.40, p.13-43, 2013.

GROSS, Neil; MEDVETZ, Thomas; RUSSEL, Rupert. "The Contemporary American Conservative Movement". Annual Review of Sociology, 37, 325-354, 2011.

HABERMAS, Jürgen. A Nova Obscuridade. São Paulo: Editora Unesp, 2015.

LIENESCH, Michael. "Right-Wing Religion: Christian Conservatism as a political movement". Political Science Quarterly, vol. 97, No 3 (Autumn), 1992.

MACHADO, Maria das Dores Campos. "O discurso cristão sobre a 'ideologia de gênero"'. Revista Estudos Feministas, Florianópolis, 26(2), 
MACHADO, Rosana Pinheiro; MAIA, Tatiana Vargas. "As Múltiplas faces do conservadorismo brasileiro". In. Revista Cult, n 234, ano 21, maio, 2018.

MARIZ, Cecilia; GRACINO JR, Paulo. “As igrejas pentecostais no Censo de 2010". in TEIXEIRA, Faustino; MENEZES, Renata (orgs). Religiões em Movimento. Petrópolis: Vozes, 2013.

MIGUEL, Luis Felipe. “Da 'doutrinação marxista' à 'ideologia de gênero': Escola Sem Partido e as leis da mordaça no parlamento brasileiro". Rio de Janeiro: Revista Direito \& Práxis, vol. 7, N. 15, 2016.

OWEN, Dennis; WALD, Kenneth; HILL, Samuel. "Authoritarian or Authority-Minded? The Cognitive Commitments of Fundamentalists and the Christian Right". Religion and American culture: A Journal of Interpretation, vol. 1, No 1 (winter), 1991.

RANDOLPHO PAIVA, ANGELA. Católico, Protestante, Cidadão: uma comparação entre Brasil e Estados Unidos. Belo Horizonte: Editora UFMG; Rio de Janeiro: IUPERJ, 2003.

RYDGREN, Jens. “The Sociology of the Radical Right”. Annual Review of Sociology, February 21, 2007.

SINGER, André. Os sentidos do Lulismo: Reforma gradual e pacto conservador. São Paulo: Companhia das Letras, 2012.ba

SWARTZ, David. Moral Minority: the evangelical left in na Age of Conservatism. University of Pennsylvania Press, 2012.

VELASCO e CRUZ, Sebastião; KAYSEL, André; CODAS, Gustavo (orgs.). Direita, volver! O retorno da direita e o ciclo político brasileiro. São Paulo: Fundação Perseu Abramo, 2015. 